\title{
BIODEGRADAÇÃO DE CORANTES E EFLUENTES TÊXTEIS POR FUNGOS
}

\section{BIODEGRADATION OF DYES AND TEXTILE EFFUELTS BY FUNGI}

\section{Aline Ramalho Brandão Pereira ${ }^{1}$, Frank Lucarini Bueno ${ }^{2}$, Samantha Cristine Santos ${ }^{3}$, Cláudio Antônio Andrade Lima ${ }^{4}$, Amanda Latércia Tranches Dias ${ }^{5}$}

\author{
${ }^{1}$ Universidade Federal de Lavras - Departamento de Biologia - Laboratório de \\ Microbiologia e-mail: aline.uflamg@gmail.com \\ ${ }^{2,4,5}$ Universidade Federal de Alfenas - Instituto de Ciências Biomédicas Laboratório \\ de Microbiologia \\ ${ }^{3}$ Universidade de São Paulo - São Carlos - Departamento de Engenharia Hidráulica e \\ Saneamento
}

\section{RESUMO}

Os resíduos da indústria têxtil se caracterizam por sua baixa degradabilidade, alto potencial mutagênico e carcinogênico, podendo atingir o meio ambiente e a saúde pública. O emprego de fungos, principalmente, basidiomicetos degradadores de lignina, tem sido cada vez mais utilizado devido à produção de enzimas ligninolíticas de baixa especificidade, que podem ser aplicadas na degradação de compostos fenólicos. A triagem de fungos provenientes de ambientes contaminados também é de grande importância para a seleção de microrganismos com potencial degradativo, pois, se os mesmos conseguem proliferar neste ambiente, certamente possuem um sistema enzimático que lhes permita metabolizar as espécies químicas presentes no local. O objetivo deste trabalho foi isolar fungos da estação de tratamento de efluentes de indústrias têxteis e avaliar a degradação de corantes e efluentes por estes fungos e por fungos com capacidade degradativa conhecida. Os fungos padrões utilizados foram Lentinula edodes e Paraconiothyrium estuarinum. Os corantes em estudo foram Remazol Brilliant Blue R (RBBR), Reactive Yellow 145, Reactive Red 195 e efluente têxtil. A mesma espécie fúngica (Geothricum candidum) foi isolada do tanque de aeração de ambas as indústrias têxteis investigadas. Foram feitos testes em meio sólido e líquido, sob diferentes condições de incubação e pH. Foi observada melhor capacidade degradativa nas amostras sob agitação. $\mathrm{O}$ fungo isolado da estação de tratamento não degradou o corante RBBR, porém, demonstrou capacidade de 
degradação do efluente em $\mathrm{pH} 9$, a $35^{\circ} \mathrm{C}$ e na presença de tampão acetato de sódio. Lentinula edodes degradou todos os corantes e efluentes, e os melhores resultados foram obtidos em $\mathrm{pH} 5$ na presença de tampão. O fungo Paraconiothyrium estuarinum não degradou o corante RBBR, porém, apresentou capacidade degradativa considerável dos corantes Reactive Yellow 145 e Reactive Red 195. A partir destes resultados, há perspectivas de utilização destes fungos no tratamento de efluentes têxteis, inoculando aqueles com capacidade degradativa conhecida durante o tratamento ou criando condições para que os existentes no local cresçam e degradem os compostos existentes.

Palavras-chave: Fungos. Efluentes têxteis. Biodegradação. Paraconiothyrium estuarinum

\section{ABSTRACT}

The residues of the textile industry are characterized by his low degradability, high mutagenesis and carcinogenic potential, could reach the environment and the public health. The use of fungi, mainly basidiomycetes lignin degraders, has been used widely, due to the production of ligninolytic enzyme of low specificity, could be used for the degradation of felonies compositions. The screen of fungi coming of the polluted environmental is also of great importance for the selection of microorganisms with potential degradative, because, if the same ones get it proliferates in this ambient, certainly they possess an enzymatic system that it allows to metabolize the present chemical species in the place. A same fungus' gender (Geothricum sp) was isolated of the aeration tank of the textile industries investigated. The capacity degradative of this fungi was evaluated with recognized capacity degradative fungi Lentinula edodes and Paraconiothyrium estuarinum front to the dyes Remazol Brilliant Blue R (RBBR), Reactive Yellow 145 and Reactive Red 195 and to the textile effluent. They were made tests in solid and liquid middle, under different incubation conditions and $\mathrm{pH}$. Better capacity degradative was observed in the samples under agitation. The isolated fungus didn't present capacity degradative of the color RBBR, however, it demonstrated capacity of the effluent degradation in $\mathrm{pH} 9$, to $35^{\circ} \mathrm{C}$, and in presence of acetate of sodium buffer. Lentinula edodes degraded all dyes and effluent, and the best results were obtained in $\mathrm{pH} 5$ and in the presence of buffer. The fungus Paraconiothyrium estuarinum didn't degrade the color RBBR, however, presented considerable degradative capacity of the dyes Reactive Yellow 145 and Reactive Red 195. To leave of those results, there are perspectives of use these fungi in treatment of textile effluents inserting fungi with capacity degradative known during the treatment, or creating conditions so that the existent ones in place grow and degrade the existent compositions.

Keywords: Fungi. Textile effluents. Biodegradation. Paraconiothyrium estuarinum 


\section{INTRODUÇÃO}

Nas últimas décadas, os problemas ambientais têm se tornado cada vez mais críticos e freqüentes, principalmente devido ao desmedido crescimento populacional e ao aumento da atividade industrial. Desta maneira, os problemas devido à ação antrópica têm atingido dimensões catastróficas, podendo ser observados através de alterações na qualidade do solo, ar e água (KUNZ et al., 2002).

A indústria têxtil desempenha um papel importante na economia de muitos países. Segundo Souza e Zamoura (2005), o fato de utilizarem grandes quantidades de água associado ao baixo aproveitamento dos insumos (corantes, detergentes, engomantes, amaciantes e outros), faz com que a indústria têxtil seja responsável pela geração de grandes volumes de resíduos, com elevada carga orgânica e forte coloração.

Os efluentes têxteis se caracterizam por serem altamente coloridos, devido à presença de corantes que não se fixam à fibra durante o processo de tingimento (KUNZ et al., 2002). No tingimento os corantes mais comumente utilizados pertencem à classe dos corantes azo e "vat". Entre os grupos químicos constituintes das classes de corantes azo estão os anéis aromáticos ligados por $\mathrm{N}=\mathrm{N}$; e os corantes "vat" constituídos por cromóforos indigóides que podem ser derivados da indigotina ou tioindigo ou cromóforos derivados basicamente da antraquinona (BALAN, 1998).

Quando não tratados adequadamente, os efluentes provenientes do processo de tingimento de fibras têxteis podem modificar o ecossistema, diminuindo a transparência da água e a penetração da radiação solar, o que pode modificar a atividade fotossintética e o regime de solubilidade dos gases (SOUZA e ZAMORA, 2005).

Os processos destinados ao tratamento de efluentes industriais objetivam a transformação das espécies responsáveis pela poluição ambiental, em formas inócuas que não ofereçam riscos de impacto ambiental. Normalmente, procura-se a redução dos principais parâmetros ambientais (cor, carga orgânica e toxicidade), de maneira a atingir os padrões de qualidade estabelecidos pelos órgãos de controle (BRITO et al., 2004). O ideal e desejável é a mineralização dos compostos a dióxido de carbono e água, obtendo assim, a completa remoção do xenobiótico (BALAN, 1998).

Em geral na indústria têxtil, os processos de tratamento de efluentes estão fundamentados na operação de sistemas físico-químicos de precipitação-coagulação, seguidos de tratamento biológico via sistema de lodos ativados. Os processos biológicos continuam sendo os mais utilizados para a biorremediação, principalmente devido a sua capacidade de aplicação em grande escala, com custos relativamente baixos (BRITO et al., 2004). Os microrganismos que agem na transformação de compostos podem usar os efluentes para a obtenção de energia para seu crescimento, como fonte de nutrientes, ou ainda possuem a capacidade de degradá-los (BALAN, 1998). 
Vários organismos podem ser utilizados na degradação como bactérias, fungos ou plantas, e a eficiência dos mesmos depende, em muitos casos, da estrutura da molécula e da presença de enzimas hábeis em degradar o produto (MEYER, 1978).

Os fungos secretam uma grande diversidade de enzimas eficientes no ambiente que são utilizadas para auxiliar sua nutrição, e desta maneira são responsáveis pela deterioração de vários materiais naturais, refinados ou processados (BENNETT, 1998). Várias enzimas não são completamente específicas aos substratos e agem sobre compostos recém sintetizados, liberados pelas atividades humanas na biosfera. Nas últimas décadas, a utilização dos fungos filamentosos e seus metabólitos nos processos de biorremediação vêm crescendo, em virtude do alto potencial degradativo, biossortivo (metais pesados e corantes) e dos mecanismos de resistência a condições ambientais adversas (CONCEIÇÃO et al., 2005).

Os caminhos atuais da biotecnologia indicam fungos basidiomicetos degradadores de lignina, como eficientes na degradação de uma grande variedade de compostos e de corantes, com alto potencial de ação na recuperação de ambientes contaminados (KAMIDA et al., 2005). A habilidade comum dos fungos da decomposição branca é oxidar compostos fenólicos, relacionados à lignina, que na maioria das vezes está associada a enzimas extracelulares ligninolíticas (MELO e AZEVEDO, 2008), como as fenoloxidases e peroxidases, que representam o maior grupo de enzimas que catalisam a oxidação de compostos aromáticos pelo oxigênio molecular reduzindo-o a água.

Assim sendo, trabalhos adicionais sobre o papel de fungos em processos de biorremediação são necessários e importantes uma vez que alterações no meio ambiente podem ocasionar interferências diretas e ou indiretas em Saúde Pública. O objetivo do presente estudo foi isolar fungos da estação de tratamento de indústrias têxteis e comparar a tolerância e degradação de corantes e efluentes têxteis pelos isolados e por fungos com capacidade degradativa conhecida.

\section{MATERIAIS E MÉTODOS}

Todos os experimentos foram realizados no laboratório de Microbiologia e Imunologia (Departamento de Ciências Biológicas) da Universidade Federal de Alfenas (UNIFAL-MG).

\subsection{Local de coleta das amostras}

A primeira estação de tratamento de efluentes (ETE-1) localiza-se no município de Alfenas, Minas Gerais. O tanque de aeração tem capacidade para $1200 \mathrm{~m}^{3}$. A aeração é do tipo convencional tratando despejos de tinturaria de fios de poliéster, com vazão média de cerca de $20 \mathrm{~m}^{3} \cdot \mathrm{h}^{-1}$, sendo a sedimentação no decantador secundário assistida quimicamente com adição de floculantes $\mathrm{e}$ polieletrólitos. 
A ETE-2 localiza-se no município de Guaranésia, Minas Gerais. É operada na modalidade aeração prolongada com sedimentação exclusivamente física, tratando despejos de lavanderia e acabamento de tecidos de algodão, com vazão média de cerca de $4 \mathrm{~m}^{3} \cdot \mathrm{h}^{-1}$.

\subsection{Fungos}

Foi realizado o isolamento de fungos das estações de tratamento de efluentes das indústrias têxteis, conforme metodologia proposta por Bergsten et al. (2005).

As amostras para isolamento de fungos foram coletadas do tanque de aeração ( $\mathrm{pH}$ 9) da estação de tratamento das duas indústrias têxteis em frascos de vidro previamente esterelizados.

Foram filtrados $50 \mathrm{~mL}$ das amostras em membrana Millipore ${ }^{\circledR} 0,45 \mu \mathrm{m}$. As membranas foram colocadas sobre placas contendo Ágar Sabouraud-dextrose (SDA) suplementado com cloranfenicol $(30 \mathrm{mg} / 100 \mathrm{~mL})$, extrato de levedura $(2 \%)$ e tiamina $(0,1 \%)$. As placas foram incubadas por um período de três dias a $256{ }^{\circ} \mathrm{C}$. Os fungos que apresentaram crescimento foram transferidos para tubos contendo Ágar Sabouraud e Cloranfenicol (30mg/100mL).

Também foram utilizados fungos com reconhecida capacidade degradativa (fungos padrões), os fungos filamentosos Lentinula edodes INCQS 40220 (fungo ligninolítico) e Paraconiothyrium estuarinum INCQS 40201 (ascomiceto), ambos doados pelo Instituto Nacional de Controle de Qualidade em Saúde (INCQS), da Fundação Oswaldo Cruz do Rio de Janeiro (FIOCRUZ), Brasil. Foram feitos testes para avaliar a capacidade degradativa destes fungos frente a corantes têxteis e ao efluente proveniente das indústrias em estudo.

\subsection{Corantes}

Os corantes usados foram o Remazol Brilliant Blue R (RBBR - Corante antraquinônico), Reactive Yellow 145, Reactive Red 195 (ambos corantes monoazo). Foi feita a varredura dos corantes em estudo, para a avaliação do comprimento de onda em que ocorre maior absorbância. Também foi feita a varredura dos corantes em diferentes $\mathrm{pHs}(\mathrm{pH} 5,0, \mathrm{pH} 9,5$ e $\mathrm{pH}$ 12,5) na presença e ausência do meio de cultura, para a análise da estabilidade da estrutura dos corantes frente a estas diferentes condições. Este estudo prévio se fez importante para a certificação de que possíveis alterações ocorridas na estrutura do corante, sejam decorrentes da ação do microrganismo em questão.

Os comprimentos de onda para leitura dos corantes e efluente no espectofotômetro foram respectivamente: Remazol Brilhant Blue - 562nm, Reactive Yellow 145- 418nm, Reactive Red 195 - 529nm e efluente têxtil: 460nm.

\subsection{Efluente Têxtil}

As amostras dos efluentes foram coletadas da caixa anterior à lagoa de lodo ativado (efluente bruto) das estações de tratamento de efluentes (ETE) das indústrias 
têxteis em estudo. Foi feita a varredura do efluente, para a avaliação do comprimento de onda em que ocorre maior absorbância.

2.5. Tolerância e capacidade de degradação de corantes em meio sólido (BERGSTEN et al., 2005).

Os fungos padrões Paraconiothyrium estuarinum, Lentinula edodes e o fungo isolado, foram inicialmente inoculados em placas contendo meio complexo Ágar malte (AM) $0,5 \%$ ( $0,5 \%$ de extrato de malte e $2 \%$ de ágar) acrescido de $200 \mathrm{ppm}$ dos três corantes em estudo, separadamente, para avaliação da adaptação do fungo ao corante. Após cinco dias de incubação a $25{ }^{\circ} \mathrm{C}$, foi retirado um disco de $5 \mathrm{~mm}$ de diâmetro da periferia da colônia das culturas, e cada um destes discos foi transferido para o centro de uma outra placa contendo Ágar Malte (MA) 0,5\% e corante em concentração de 300 ppm.

Em seguida, as placas foram incubadas ao abrigo da luz por 7 dias a $25^{\circ} \mathrm{C}$. Ao final deste período de incubação, o diâmetro da colônia e o halo formado em torno dela, resultado da degradação do corante, foram medidos. Como controles foram usados placas contendo apenas o meio de cultura e corante, sem adição do inóculo.

2.6. Capacidade de degradação dos corantes em meio líquido (BERGSTEN et al., 2005).

O fungo padrão que apresentou maior capacidade degradativa dos corantes em meio sólido, foi selecionado para os testes de degradação em meio líquido, visando a comparação com o fungo isolado da estação de tratamento.

Os fungos foram inicialmente inoculados em placas contendo meio complexo ágar malte $(\mathrm{AM}) \quad 0,5 \%(0,5 \%$ de extrato de malte e $2 \%$ de ágar). Após 5 dias de incubação a $25{ }^{\circ} \mathrm{C}$, foram retirados dois discos de $5 \mathrm{~mm}$ de diâmetro da periferia da colônia contendo a amostra fúngicas e transferidos para Erlenmeyers contendo $50 \mathrm{~mL}$ de extrato de malte (2\%) e $100 \mathrm{ppm}$ dos corantes em estudo. Os testes foram feitos em presença agitação (16.38 g unid.), em $\mathrm{pH} 5$ e pH 9 ( $\mathrm{pH}$ presente no tanque de aeração das indústrias têxteis em estudo), e na presença e ausência de tampão acetato de sódio ( $1 \mathrm{~mL}$ de tampão para $300 \mathrm{~mL}$ de meio). Para o corante RBBR, o mesmo teste foi realizado na ausência de agitação.

Foi utilizado como controle, o meio de cultura contendo extrato de malte e corante sem o inóculo. O período de tempo total do estudo foi de 15 dias. De dois em dois dias, uma alíquota de $5 \mathrm{~mL}$ do meio foi filtrada em membrana $0,45 \mu \mathrm{m}$ e a descoloração monitorada espectrofotometricamente pelo decréscimo do pico de absorbância a 562nm (corante RBBR), a 418nm (Reactive Yellow 145) e a 529nm (Reactive Red 195). 


\subsection{Descoloração do efluente (BERGSTEN et al., 2005)}

O fungo padrão que apresentou maior capacidade degradativa dos corantes em meio sólido, foi selecionado para os testes de degradação de efluentes têxteis, visando a comparação com o fungo isolado da estação de tratamento.

Os testes foram feitos nas mesmas condições dos realizados com os corantes. Os discos de colônias fúngicas eram, entretanto, transferidos para Erlenmeyers contendo meio complexo MA $0,5 \%$ acrescido de $50 \mathrm{~mL}$ de efluente líquido, ao invés de corante. Foi utilizado como controle, o meio de cultura contendo extrato de malte e efluente sem o inóculo. A descoloração foi monitorada pelo decréscimo do pico de absorbância a 460nm.

Os testes com o fungo isolado dos tanques de aeração, Geotrichum Candidum, foram realizados nas temperaturas de $25{ }^{\circ} \mathrm{C}$ e $35{ }^{\circ} \mathrm{C}$, devido ao fato de possuírem aspecto leveduriforme e apresentarem melhor crescimento nesta segunda temperatura.

\section{RESULTADOS E DISCUSSÃO}

Após as análises dos resultados (Figuras 1 a 6), pode-se verificar que os corantes e efluente em estudo são $\mathrm{pH}$ estáveis, ou seja, não há alteração do pico de absorbância dos mesmos coma alteração do pH. Assim, qualquer alteração observada na estrutura do corante pode ser decorrente da ação das enzimas produzidas pelo microrganismo em questão.

Também se pode observar que o pico de absorbância obtido após a varredura dos corantes não é modificada pela adição do meio de cultura extrato de malte.

- Remazol Brilhant Blue

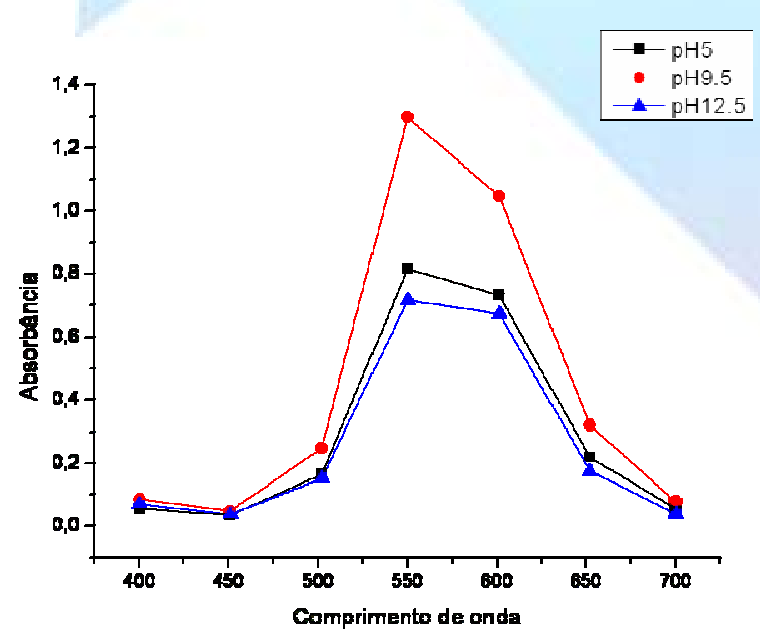

Figura 1. Gráfico de varredura do corante Remazol Brilhant Blue (100ppm) em diferentes valores de pHs (5, $9,5$ e 12,5$)$.

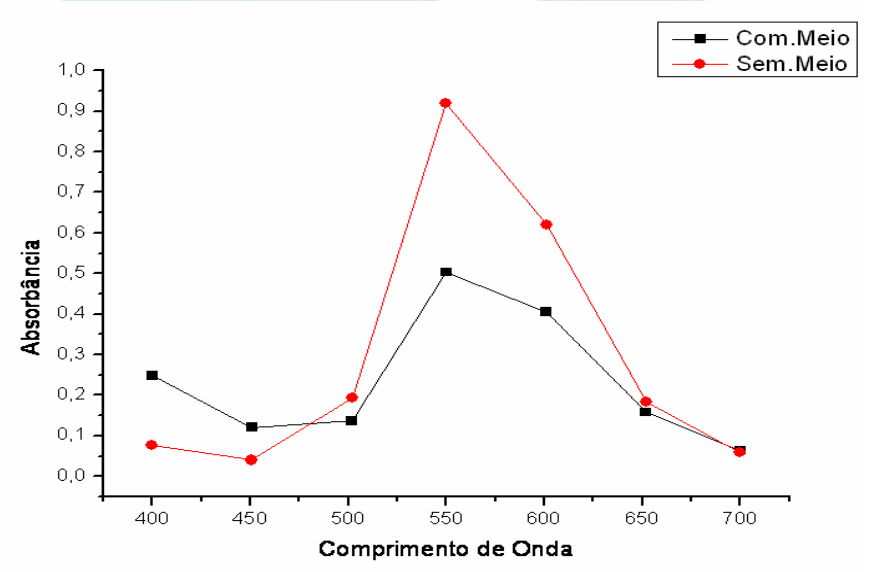

Figura 2. Gráfico de varredura do corante Remazol Brilhant Blue (100ppm) com e sem meio de cultura Extrato de Malte. 
- $\quad$ Reactive Yellow 145

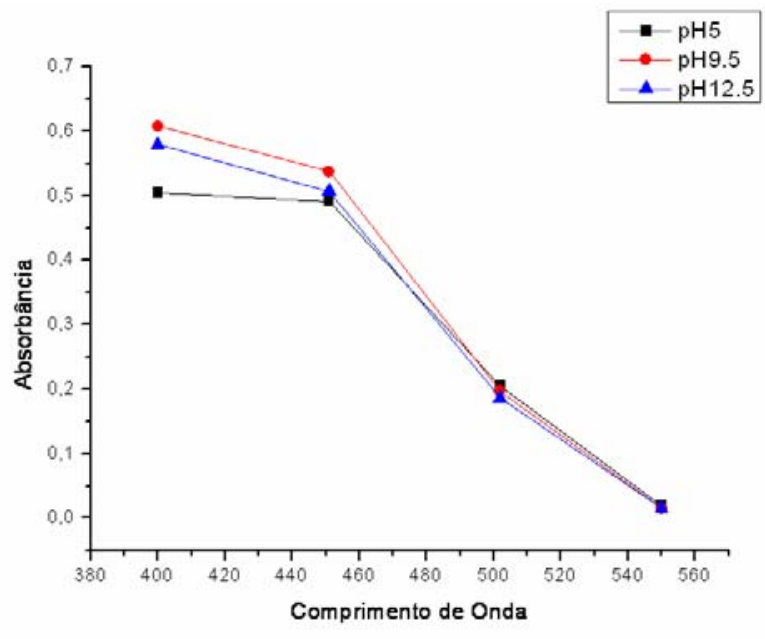

Figura 3. Gráfico de varredura do corante Reactive Yellow 145 (100ppm) em diferentes pHs (5, 9,5 e $12,5)$.

- $\quad$ Reactive Red 195

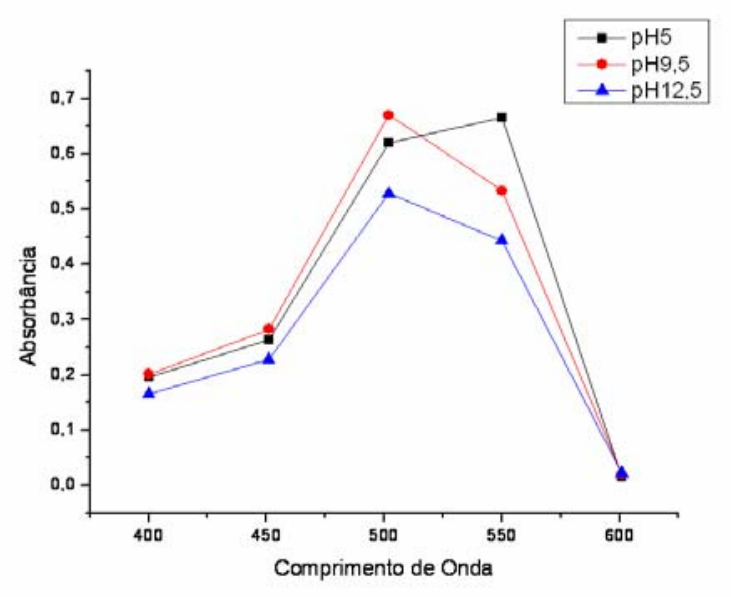

Figura 5. Gráfico de varredura do corante Reactive Red 195 (100ppm) em diferentes pHs (5, 9,5 e 12,5).

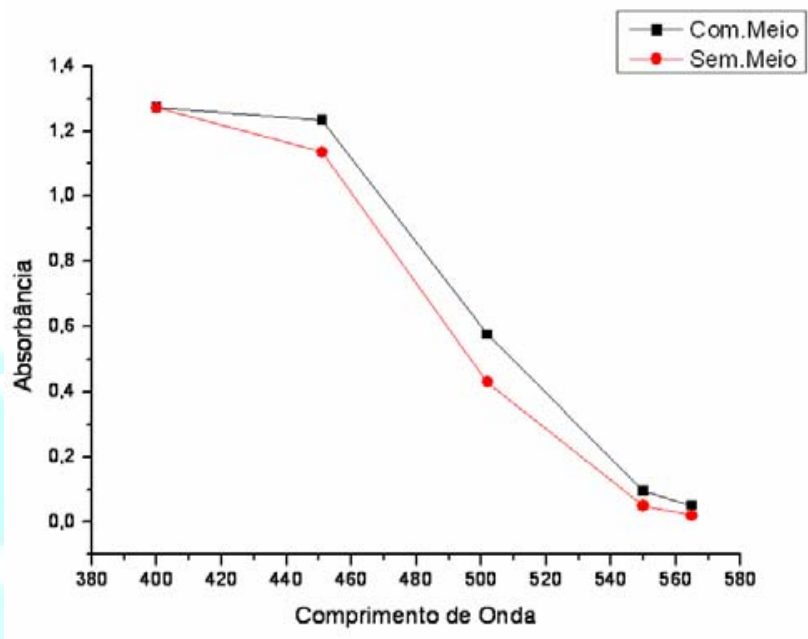

Figura 4. Gráfico de corante Reactive Yellow 145 (100ppm) com e sem meio de cultura Extrato de Malte.
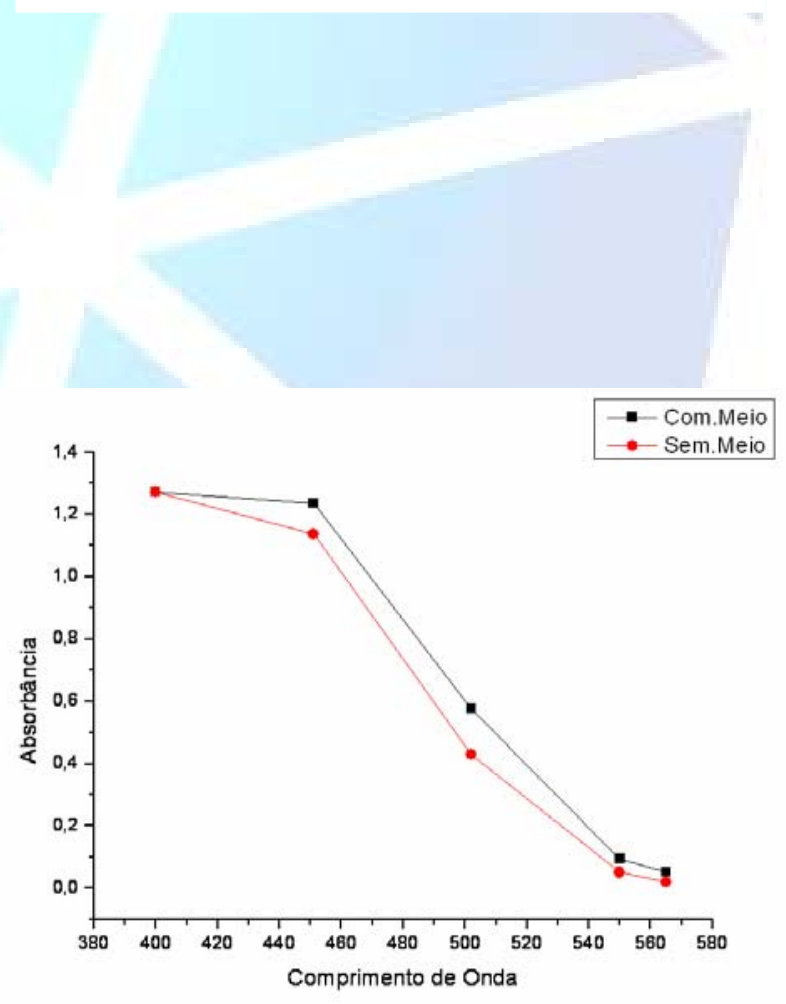

Figura 6. Gráfico de varredura do corante (100ppm) com e sem meio de cultura Extrato de Malte. 


\subsection{Isolamento de fungos}

Foram isoladas amostras fúngicas provenientes do tanque de aeração de cada indústria têxtil estudada e identificada como Geothricum candidum. Segundo García et al. (1998), este fungo é um ótimo degradador de compostos fenólicos.

\subsection{Tolerância e degradação de corantes em meio sólido}

O fungo L. edoddes, usado como padrão, descoloriu totalmente os corantes em estudo após 12 dias de incubação a $25^{\circ} \mathrm{C}$. Este resultado corroborou com aquele obtido por Bergsten et al. (2005), que obteve total degradação do corante Remazol vermelho RB na concentração de 300ppm promovida pelo mesmo fungo após 12 dias de incubação. Observou ainda que L.edoddes foi capaz de degradar vários corantes, incluindo os do tipo azo, como Vermelho Congo, Azul Tripan e Preto Amido (200ppm), após 18 dias de incubação. Esses resultados se devem principalmente a ação das enzimas ligninolíticas deste fungo da podridão branca, principalmente da lacase (BALAN,1998).

Nos resultados aqui encontrados, $P$. estuarinum degradou parcialmente os corantes Reactive yellow e Reactive red. O fungo não apresentou capacidade degradativa do corante RBBR, mostrando apenas tolerância ao mesmo. Segundo Bergsten et al. (2005), após este mesmo fungo ser testado na presença de Remazol Vermelho RB (300pm), não obteve crescimento igual ou superior ao seu controle. Apesar desse resultado, foi realizado outro teste na presença de $500 \mathrm{ppm}$ de Remazol Azul Turquesa e houve crescimento igual ao do controle, sendo, portanto, considerado tolerante. Essa variação de tolerância pode ser devida à maior toxicidade do Remazol Vermelho RB, um composto azo, em relação ao Remazol Azul Turquesa, fitalocianina de cobre, que é um composto menos tóxico.

O fungo isolado do tanque de aeração em estudo, Geothricum candidum, não apresentou atividade degradativa, mas teve capacidade adsortiva, apresentando então, apenas tolerância aos mesmos.

\subsection{Degradação de corantes em meio líquido}

O fungo padrão selecionado para o teste de degradação de corantes e efluentes que apresentou maior capacidade de degradação dos corantes em meio sólido foi o Lentinula edoddes.

Os resultados obtidos sem agitação (Figura 7), mostram um percentual de 77\% de degradação do corante RBBR e grande adsorção desse corante pelo fungo. 


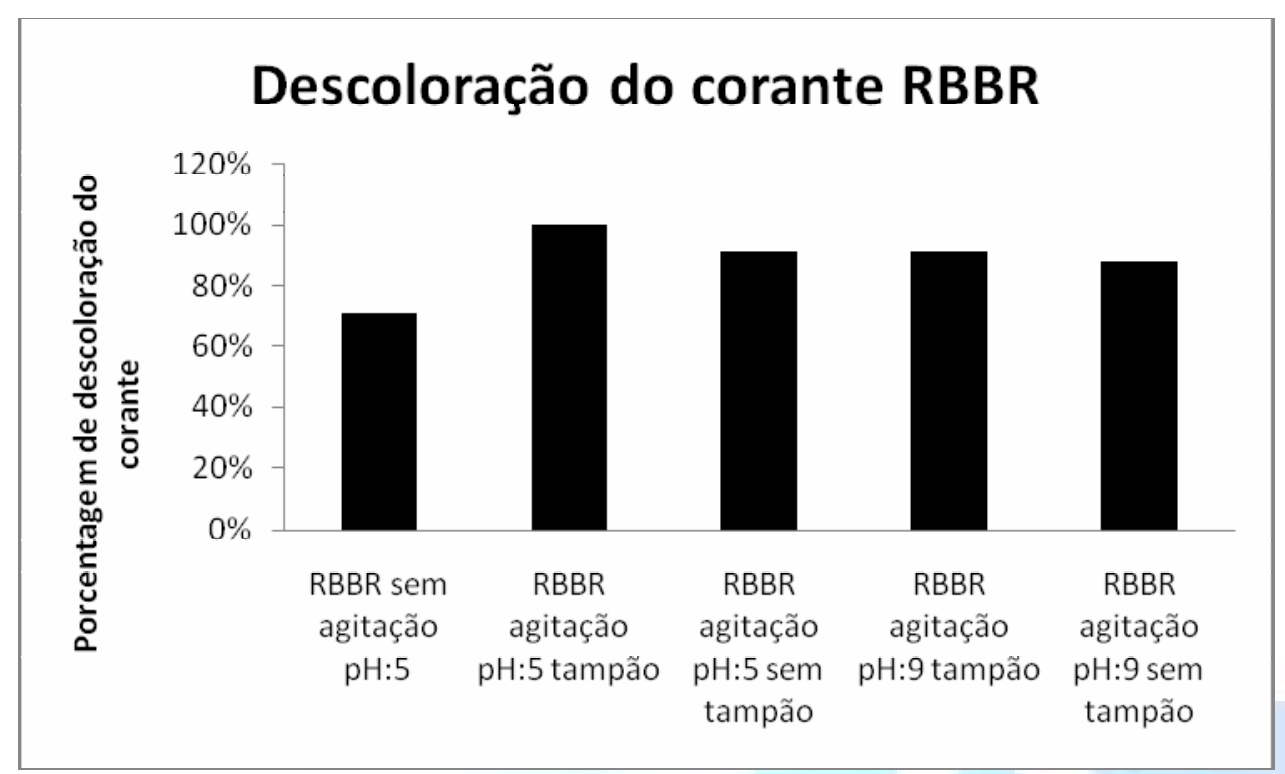

Figura 7. Degradação do corante Remazol Brilhant Blue pelo fungo Lentinulla edodes em agitação e na ausência de agitação, em diferentes pHs e na presença e ausência de tampão acetato de sódio, após 15 dias de incubação.

Para o corante RBBR, Em pH 5 e com adição de tampão, foi observado 100\% de descoloração. $\mathrm{Na}$ ausência deste último, no mesmo $\mathrm{pH}$, houve $92 \%$ de descoloração. Neste pH não foi observada adsorção do corante pelo fungo. Em pH 9, com adição de tampão, houve $91 \%$ de descoloração e na ausência do mesmo, $86 \%$ de descoloração, entretanto foi observada muita adsorção do corante pelo fungo.

Com relação ao corante Reactive Yellow (145), em pH5, com adição de tampão, foram observados $73 \%$ de descoloração e muita adsorção do corante pelo fungo (Figura 8). Em sua ausência, no mesmo pH, houve $61 \%$ de descoloração e também, muita adsorção do corante pelo fungo. Em pH 9, com adição de tampão, houve $61 \%$ de descoloração e na ausência do mesmo, $41 \%$ de descoloração. Neste mesmo $\mathrm{pH}$, foi observada pouca adsorção do corante pelo fungo. 


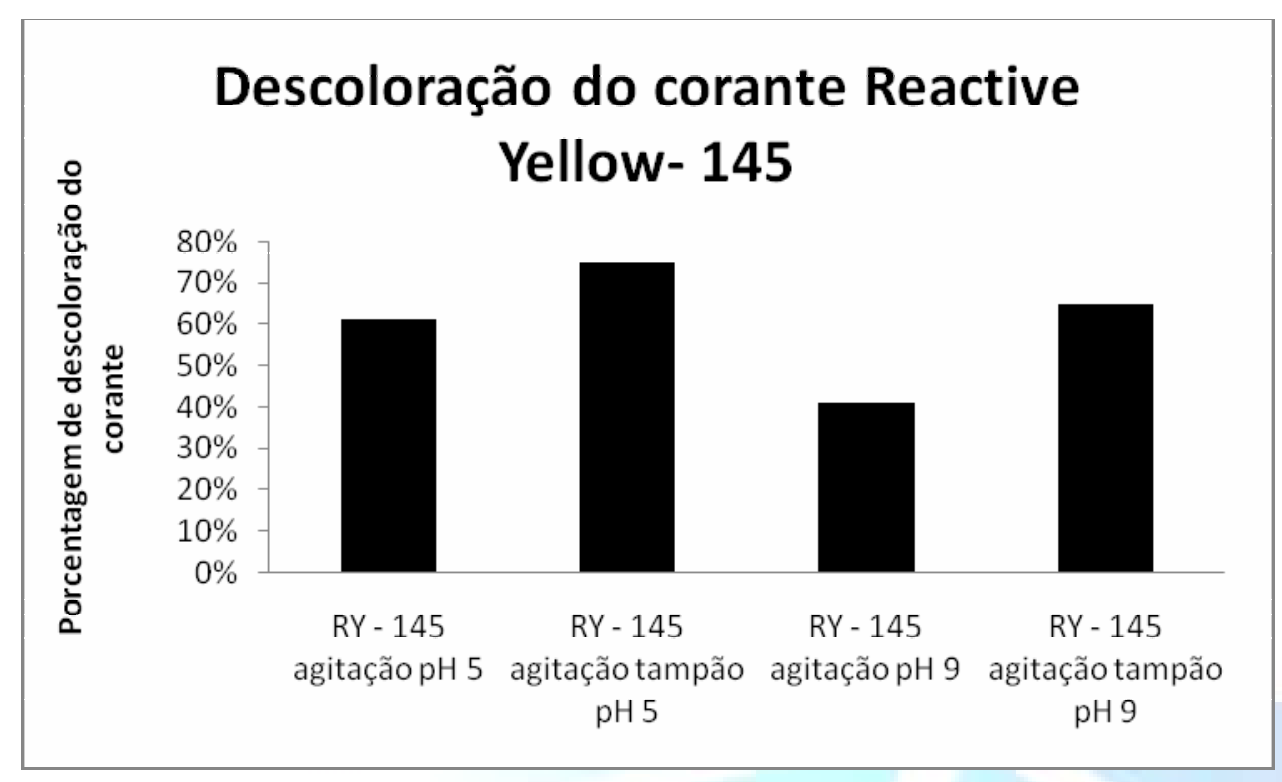

Figura 8. Degradação do corante Reactive Yellow 145 pelo fungo Lentinulla edodes em agitação, em diferentes pHs e na presença e ausência de tampão acetato de sódio, após 15 dias de incubação.

Quanto ao uso do corante Reactive red 195, em pH 5 e com adição de tampão, foi observado 89\% de descoloração (Figura 9). Em sua ausência, no mesmo pH, houve $49 \%$ de descoloração, e, em ambos, muita adsorção dos corantes pelo fungo. Em pH 9 e com adição de tampão, foram observados 81\% de descoloração. $\mathrm{Na}$ ausência deste último ocorreram $83 \%$ de descoloração e muita adsorção do corante pelo fungo.

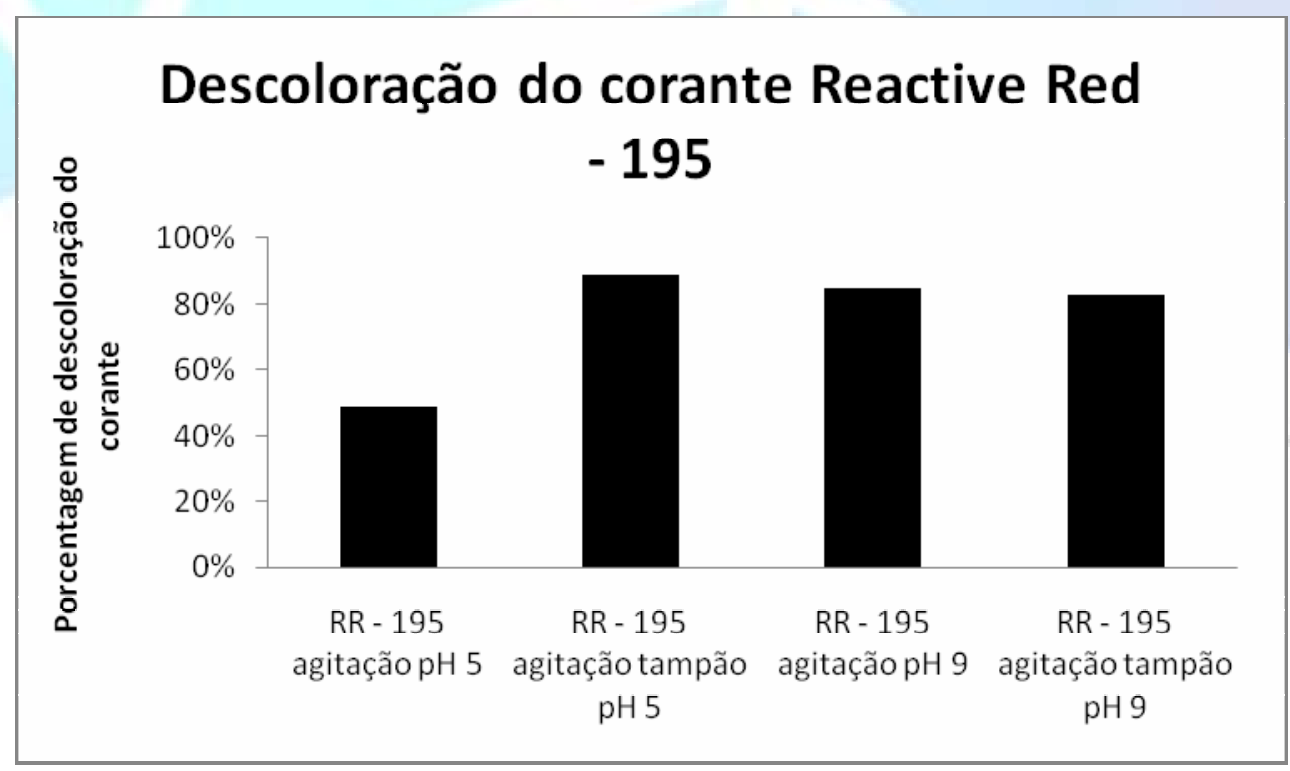

Figura 9. Degradação do corante Reactive Red 195 pelo fungo Lentinulla edodes em agitação, em diferentes pHs e na presença e ausência de tampão acetato de sódio, após 15 dias de incubação.

No uso do efluente têxtil, em pH 5, com adição de tampão, foram observados 91\% de descoloração (Figura 10). Em sua ausência, no mesmo pH, houve 71\% de 
descoloração. Neste $\mathrm{pH}$ foi observada pouca adsorção dos corantes pelo fungo. Em pH 9, com adição de tampão, ocorreram $31 \%$ de descoloração, e na ausência do mesmo, $36 \%$ de descoloração. Em pH 9 foi verificada mais adsorção do corante pelo fungo em relação ao $\mathrm{pH} 5$.

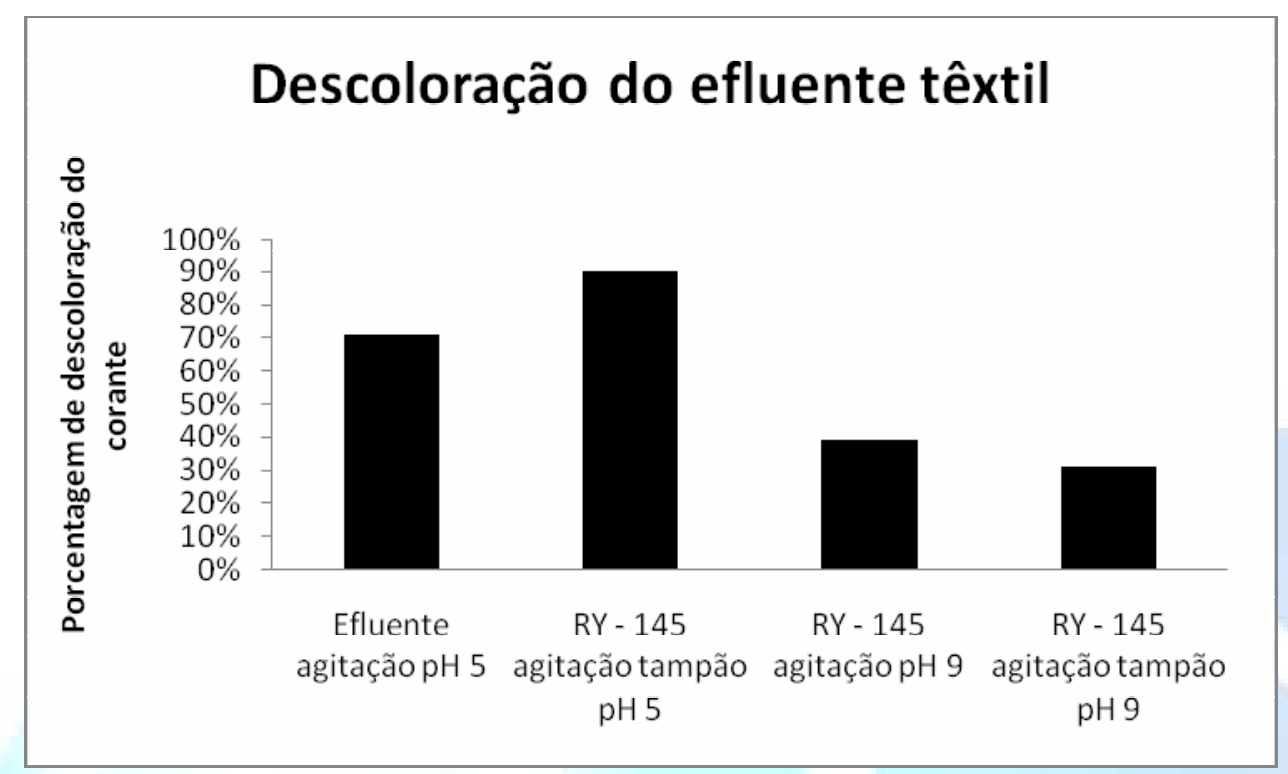

Figura 10. Degradação de efluente têxtil pelo fungo Lentinulla edodes em agitação, em diferentes pHs e na presença e ausência de tampão acetato de sódio, após 15 dias de incubação.

Em todos os cultivos realizados, o pH 5 manteve-se constante, até mesmo na ausência do tampão. $\mathrm{O}$ pH 9 não se manteve, mesmo na presença do tampão, caindo para aproximadamente $\mathrm{pH} 8$.

O melhor resultado de degradação dos corantes em meio líquido foi obtido em agitação, pH 5 e na presença do tampão, pois, a primeira garante maior oxigenação favorecendo crescimento fúngico, o que interfere diretamente nas reações enzimáticas, podendo tal fato, estar associado à maior taxa de degradação do corante. Segundo Dritsa e Rigas (2005), a descoloração de uma variedade de corantes em culturas em agitação é maior do que culturas mantidas em repouso. Além disso, menos adsorção dos corantes pelo fungo é observada em culturas mantidas em agitação. A presença do tampão não se mostrou necessária para a manutenção do $\mathrm{pH}$ 5, cujo valor é descrito como sendo ideal para a ação das enzimas ligninolíticas produzidas pelo fungo (SWAMY e RAMSAY 1999). Os maiores valores de degradação, entretanto, foram obtidos na presença do tampão acetato de sódio. Esses mesmos autores compararam a eficiência da degradação de corantes por fungos ligninolíticos pela adição de diferentes tampões, e obtiveram os melhores resultados da degradação na presença do tampão acetato de sódio.

$\mathrm{O}$ efluente foi degradado com maior eficácia em agitação, em $\mathrm{pH} 5$ e na ausência do tampão. A presença de agitação e ausência do tampão simulam as condições do tanque de aeração das indústrias, mostrando que o fungo em estudo poderia ser usado na degradação dos efluentes têxteis. Outros autores estudaram a 
capacidade de descoloração por outro fungo ligninolítico ( $P$. chrysosporium) frente a uma amostra de efluente simulada em laboratório e observaram a descoloração total após 7 dias de tratamento (KIRBY e COL, 1995 apud KUNZ et al., 2002).

3.4. Degradação do corante RBBR e de efluente pelo fungo isolado do tanque de aeração Geotrichum candidum:

Em pH 5 o fungo não apresentou capacidade degradativa em ambas as temperaturas. Em pH 9, não apresentou capacidade degradativa do corante RBBR, entretanto, apresentou esta capacidade degradativa do efluente $(36,5 \%)$ a $35^{\circ} \mathrm{C}$. Provavelmente, este resultado se deve a ação da enzima peroxidase que segundo Kim e Shoda, (1998), é produzida por esse gênero de fungo, e é uma das enzimas na descoloração de corantes. Vale ressaltar, que as condições simuladas em laboratório, em que o fungo em questão demonstrou maior capacidade degradativa, são as existentes no ambiente em que ele foi isolado (tanque de aeração), mostrando assim, que provavelmente esse microrganismo possua um importante papel na degradação do efluente das ETEs em estudo.

\section{CONCLUSÕES}

Foram isoladas linhagens fúngicas das estações de tratamento das indústrias têxteis, identificadas como Geothricum candidum .

Lentinula edodes apresentou tolerância e maior capacidade de degradação dos corantes RBBR, Reactive Yellow 145 e Reactive Red 195 em meio sólido em relação aos fungos $G$. candidum e Paraconiohyrium estuarinum. O fungo isolado $G$. candidum não degradou os corantes em meio sólido, entretanto, apresentou tolerância a estes corantes verificados pelo seu crescimento na presença dos mesmos.

Em relação aos testes de degradação de corantes em meio líquido e de efluentes, o fungo padrão $L$. edodes apresentou melhor capacidade degradativa em relação ao fungo isolado $G$. candidum. A partir destes resultados, há perspectivas da utilização destes fungos na degradação de corantes e efluentes têxteis, seja inserindo fungos com capacidade degradativa conhecida (L. edodes) durante o tratamento, ou criando condições para que os microrganismos existentes no próprio local ( $G$. candidum) cresçam e degradem os corantes presentes no efluente.

\section{AGRADECIMENTOS}

Os autores agradecem a Manuela da Silva - INCQS FIOCRUZ-RJ, pela concessão das amostras fúngicas, ao prof. Dr. Ludwig Heinrich Pfenning - UFLA MG, pela identificação do fungo isolado do tanque de aeração e ao Prof. Dr. Carlos Renato Corso - UNESP Campus de Rio Claro, pelas sugestões. 


\section{REFERÊNCIAS}

BALAN, D.S.L. Biodegradação e toxicidade de efluentes têxteis: Corante índico.1998. 130 f. Tese (Doutorado em Ciências Biológicas) - Instituto de Biociências, Universidade Estadual Paulista, Rio Claro,1998.

BENNETT, J.W. Mycotechnology: the role of fungi in biotechnology. Journal of Biotechnology, v.66, p.101-107, 1998.

BERGSTEN, L.R.; MACHADO,M.E.S.; GATTI, M.J.A.; NISHIKAWA, M.M.; BAPTISTA, D.F.; SILVA, M. Estudo de fungos isolados de sedimento contaminado por compostos tóxicos. Revisa, v.1, p. 185-191, 2005.

BRITO, N.N.; ZAMORA, P.P.; NETO, A.L.O.N.; BATTISTI, A.; PATERNIANI, J.E. S.; PALEGRINI, R.T. Utilização de fungos na remediação de efluentes industriais. IV Fórum de Estudos Contábeis, 2004.

CONCEIÇÃO, D.M.; ANGELIS, D.A.; BIDOIA, E.D.; ANGELIS, D.F. Fungos filamentosos isolados do rio Atibaia, SP e refinaria de petróleo biodegradadores de compostos fenólicos. Arquivos do Instituto Biológico, v. 72, n.1, p. 99-106, 2005.

DRITSA, V.; RIGAS, F. Decolourisation of a polymeric dye by selected fungal strains in liquid cultures. Enzyme and Microbial Technology, v.39, p.120-124, 2005.

GARCIA, G.; VENCESLADA, J. L. B.;PEÑA, P. R.; GÓMEZ, R. Biodegradation of phenol compounds in vinasse using Aspergillus terreus and Geotrichum candidum. Departamento de Ingeniería Química, Facultad de Ciencias, Universidad de Córdoba, Avda San Alberto Magno s/n, E-14004 Córdoba, Spain. 1998.

KAMIDA, H.M.; DURRANT, L.R.; MONTEIRO, R.T.R.; ARMAS, E.D. Biodegradação de efluente têxtil por Pleurotus sajor-caju. Química Nova, v. 28, n.4, p. 629-632, 2005.

KIM, S.J.; SHODA, M. Purification and Characterization of a Novel Peroxidase from Geotrichum candidum Dec 1 Involved in Decolorization of Dyes. Applied and Environmental Microbiology, v. 65, n.3, p.1029-1035, 1998.

KUNZ, A.; ZAMORA, P.P.; DURÁN, S.G.M.N. Novas tendências no tratamento de efluentes têxteis. Química Nova, v. 25, n.1, p. 78-82, 2002. 
MELO, I.S.; AZEVEDO, J.L. Microbiologia Ambiental, 2a ed.. Rev. Ampl., Jaguariúna: Embrapa Meio Ambiente, 2008, 647p.

MEYER, U. Biodegradation of synthetic organic colorants. In: Brown, A.W.A., Ecology of Pesticides, John Willey, New York, 1978, p. 525.

SOUZA, C.R.L.; ZAMORA, P.P. Degradação de corantes reativos pelo sistema ferro metálico/peróxido de hidrogênio. Química Nova, v. 28, n.2, p. 226-228, 2005.

SWAMY, J.; RAMSAY, A. The evaluation of white rot fungi in the decoloration of textile dyes. Enzyme and Microbial Technology, v. 24, p.130-137, 1999. 